\title{
Clinicopathological features of granulomatous lobular mastitis and mammary duct ectasia
}

\author{
LIYU JIANG $^{1 *}$, XIAOYAN LI $^{1 *}$, BORUI SUN ${ }^{1,2}$, TINGTING MA $^{1}$, XIAOLI KONG ${ }^{1}$ and QIFENG YANG ${ }^{1,3}$ \\ ${ }^{1}$ Department of Breast Surgery, Qilu Hospital, Shandong University, Jinan, Shandong 250012; \\ ${ }^{2}$ Department of Anesthesiology, First Affiliated Hospital of Xi'an Jiaotong University, Xian, Shanxi 710061; \\ ${ }^{3}$ Department of Pathology Tissue Bank, Qilu Hospital, Shandong University, Jinan, Shandong 250012, P.R. China
}

Received December 1, 2018; Accepted September 11, 2019

DOI: $10.3892 /$ ol.2019.11156

\begin{abstract}
Granulomatous lobular mastitis (GLM) and mammary duct ectasia (MDE) are inflammatory diseases. However, only a limited number of studies have focused on characterizing their clinicopathological features. The aim of the present study was to investigate the etiology, clinicopathological characteristics and diagnosis of GLM and MDE. The clinical information and treatment of 118 female patients with pathologically-proven GLM or MDE were retrospectively analyzed in the present study. A total of 29 cases had GLM, 77 had MDE and 12 had GLM accompanied by MDE. GLM tends to occur in patients who have had their last birth within 5 years and are usually $<40$ years of age. GLM masses were usually larger than MDE masses and suppurated or ulcerated more easily. Histopathologically, GLM was characterized by a significant granulomatous inflammatory reaction centered on lobules. Compared with MDE, GLM had a higher incidence of granuloma and microabscess formation within the lobules and surrounding tissue. More multinucleated giant cells within granuloma were observed in patients with GLM than in those with MDE, while MDE was characterized by significant dilatation of the duct terminals and inflammatory changes in the duct wall and periductal tissues. When compared with patients with GLM, foam cells within the duct epithelium or surrounding stroma were more common in patients with MDE. The present study demonstrated that GLM and MDE had distinct clinicopathological characteristics. Further research is required in order to identify more appropriate treatment strategies for these specific types of breast inflammation.
\end{abstract}

Correspondence to: Dr Qifeng Yang, Department of Breast Surgery, Qilu Hospital, Shandong University, 107 West Wenhua Road, Jinan, Shandong 250012, P.R. China

E-mail: qifengy_sdu@163.com

${ }^{*}$ Contributed equally

Key words: granulomatous lobular mastitis, mammary duct ectasia, pathology, diagnosis

\section{Introduction}

Granulomatous lobular mastitis (GLM) is a rare idiopathic chronic inflammatory lesion of the breast that usually masquerades as breast carcinoma, both clinically and mammographically (1). It was first described as a separate entity by Kessler and Wolloch (1) in 1972, although certain cases describing GLM may also have been reported before 1972 (1-3). The term 'postpartum lobular granulomatous mastitis' was proposed by Davies and Burton (4) 10 years later. Considering that certain cases developed GLM 15 years after their last pregnancy, the term 'GLM' was formally recommended in 1987 by Going et al (5). This term described the distinctive histological features of GLM more accurately, avoiding the vagueness of 'granulomatous mastitis' (5). GLM is also known today as idiopathic GLM (6). The etiology and pathogenesis of GLM remains unclear. An association with pregnancy, lactation, local autoimmune processes, infection, hyperprolactinemia and chemical reaction induced by oral contraceptive pills has been reported in the literature (4,7-10). The clinical and radiological features of GLM are very similar to those of breast carcinoma. The most common clinical manifestation is a unilateral, tender, painful, extra-areolar breast lump $(11,12)$. Histopathologically, centrilobular granulomas and microabscess formation may be observed $(13,14)$. Granulomatous lobulitis is not associated with trauma, specific infection or exogenous material (1). GLM treatment is associated with recurrent risks that may require close medical attention for long periods of time (15). Management strategies include observation, steroids, and partial or total mastectomy (16). Complete excision of inflammatory tissue is the most effective treatment method, but systemic corticosteroids, methotrexate and antibiotics can also have an effect (6).

Despite the lack of definite epidemiological evidence of ethnic predisposition, a prevalence of GLM in specific racial populations has been observed $(17,18)$. GLM is not absent in Chinese populations, but it is usually hard to differentiate from mammary duct ectasia (MDE). A retrospective controlled study was performed in order to further illustrate the clinicopathological features of GLM and MDE. The authors' experiences on therapeutic strategies for GLM have also been presented in this paper. 


\section{Materials and methods}

Patients. The patients included in the present study were 118 women aged 15-55 years, who underwent treatment in the Qilu Hospital of Shandong University between January 2010 and January 2012. Written informed consent was obtained from all patients prior to the study start. The present study was approved by the Ethics Committee on Scientific Research of Shandong University Qilu Hospital (Jinan, China). In order to confirm the diagnosis, slides of all cases were reviewed by a prudent pathologist of our hospital; 29 cases were histopathologically diagnosed as GLM, 77 as MDE and 12 as GLM accompanied with MDE. They were divided into the GLM, MDE and overlapping groups, respectively, according to their histological characteristics.

The individual medical history of all cases, including age, smoking, pregnancy, parity, lactation, abortion, time since the patient last gave birth, family history of breast cancer, oral contraceptive and ethnic background, was reviewed. The clinical manifestations, including mass, nipple retraction, galactorrhea, abscess formation, skin ulcers, peau d'orange, pain and enlargement of ipsilateral axillary lymph nodes, were all considered. Sonography, mammography and fine needle aspiration were performed selectively, depending on the symptomology. The previous history and combined disease were elucidated simultaneously.

All patients underwent surgery with or without preoperative antibiotics. Appropriate surgery, such as lumpectomy, segmental mastectomy, subcutaneous mastectomy or subtotal mastectomy, was performed based on the extent of the lesion of each individual. A decline in the risk of recurrence was observed following wide resection. Follow-ups were carried out and continued 2 years after the patients' hospitalization.

Histopathological evaluation. The hematoxylin and eosin-stained paraffin histological sections were evaluated in detail. All the sections were obtained and stained when the surgery was performed. The paraffin-embedded specimens were deparaffinized, then submerged into citrate antigen retrieval buffer, and heated for antigen retrieval for $8 \mathrm{~min}$. The sections were then treated with $3 \%$ hydrogen peroxide at $37^{\circ} \mathrm{C}$ for $10 \mathrm{~min}$ to inactivate the endogenous peroxidase. All the terms are listed as follows: Duct dilation, periductal inflammation, periductal fibrosis, intraductal secretion, ductal hyperplasia, periductal or intralobular infiltration of inflammatory cells, intralobular microabscess formation and perilobular granulomatous inflammation, granuloma or microabscess formation in the surrounding tissue, multinuclear giant and foam cell infiltration in the surrounding tissue, necrosis. In the present study, GLM was defined as 'perilobular granulomatous inflammation, accompanied by predominant infiltration of neutrophils with or without intralobular microabscess formation'. MDE was defined as 'periductal inflammation characterized by extralobular irregular ductal dilation with periductal fibrosis'. Special staining and identification of microorganisms was not performed in the present study.

Statistical analysis. Experiments were performed in triplicate, and all data were analyzed using SPSS statistical software (version 18.0; SPSS Inc.). The data are presented as the mean \pm standard deviation. $\chi^{2}$ test was used for group comparisons between categorical variables such as age, time of abortion. The P-value was adjusted for multiple comparisons. ANOVA and a Games-Howell post-hoc pairwise comparison were used for group comparisons between continuous variables. $\mathrm{P} \leq 0.05$ was considered to indicate a statistically significant difference.

\section{Results}

During the study period, 1,173 patients were histopathologically diagnosed with benign breast disease in Department of Breast Surgery, Qilu Hospital. GLM accounted for $\sim 3.5 \%$ (41/1,173, including 12 patients diagnosed with GLM accompanied by MDE) of all the homochromous benign breast diseases in the results of the present study. All 118 patients included in the present study were Han Chinese, without a history of smoking. No patient had a history of oral contraceptive use.

Patients were divided into three groups, according to their histopathological characteristics: GLM, MDE and overlapping groups. The GLM group contained patients with perilobular granulomatous inflammation, accompanied by predominant infiltration of neutrophils with or without intralobular microabscess. The MDE group contained patients with periductal inflammation characterized by extralobular irregular ductal dilation with periductal fibrosis. The overlapping group contained patients diagnosed with GLM, accompanied by MDE.

The age of the 29 patients in the GLM group ranged from 15-53 years, with an average age of 31 years. A total of 28 cases were aged $<40$ years, and 27 had a history of both pregnancy and parity. The highest number of pregnancies and number of times giving birth was three. All 27 parous women had a history of lactation. Of the 27 patients, nine had a history of abortion with the largest frequency up to two times. The date of last delivery for 32 patients had been within the last 5 years. The majority of data from the MDE group were similar to those from the GLM group, as presented in Table I. However, the percentage of patients who had given birth within the last 5 years in the MDE group was lower than that in the GLM group. In the overlapping group, $3 / 12$ patients were $>40$ years old, with $50 \%$ of the last births occurring within the last 5 years. In addition, as a duct-centered process, the central portion of the breast was more frequently affected in the duct ectasia group, while in the GLM group, the breast peripheral parts were more frequently affected. The location of the lesions within the breast was analyzed, as it can also help distinguish among the three diseases. The data revealed that the duct ectasia lesions were more common in the central duct of the breast than the GLM lesions $\left(\chi^{2}=9.345 ; \mathrm{P}=0.002\right)$. The medical history of the 118 cases was thoroughly reviewed. A total of four patients had previously suffered from pituitary adenoma and three patients had received pituitary adenoma resection. All four cases had been histopathologically diagnosed with MDE. The serum prolactin level dropped to normal in one patient following surgery, while that of the other three patients remained twice as high as the upper limit of the normal value. Another patient had a history of schizophrenia for 14 years and underwent continuous treatment with risperidone and neurolithium. This patient was diagnosed with GLM accompanied by MDE. 
Table I. Clinical characteristics of GLM, MDE and overlapped groups.

\begin{tabular}{|c|c|c|c|c|c|c|}
\hline \multirow[b]{2}{*}{ Characteristics } & \multirow[b]{2}{*}{ GLM $(n=29)$} & \multirow[b]{2}{*}{$\operatorname{MDE}(n=77)$} & \multirow[b]{2}{*}{ Overlapped (n=12) } & \multicolumn{3}{|c|}{ P-value } \\
\hline & & & & $\begin{array}{l}\text { GLM vs. } \\
\text { MDE }\end{array}$ & $\begin{array}{l}\text { GLM vs. } \\
\text { overlapped }\end{array}$ & $\begin{array}{l}\text { MDE vs. } \\
\text { overlapped }\end{array}$ \\
\hline Age & & & & 0.052 & $0.034^{\mathrm{a}}$ & 0.576 \\
\hline Mean (range), years & $31(15-53)$ & $35(18-55)$ & $34(24-44)$ & & & \\
\hline$\leq 40$ years, $\mathrm{n}(\%)$ & $28(96.6)$ & $63(81.8)$ & $9(75.0)$ & & & \\
\hline$>40$ years, $\mathrm{n}(\%)$ & $1(3.4)$ & $14(18.2)$ & $3(25.0)$ & & & \\
\hline Pregnancy history, n (\%) & $27(93.1)$ & $71(92.2)$ & $12(100.0)$ & 0.876 & 0.351 & 0.317 \\
\hline $\begin{array}{l}\text { Frequency of } \\
\text { pregnancy, } n \text { (range) }\end{array}$ & $1.96(1-3)$ & $2.23(1-6)$ & $2.58(1-8)$ & 0.389 & 0.155 & 0.338 \\
\hline Delivery, n (\%) & $27(93.1)$ & $71(92.2)$ & $12(100.0)$ & 0.876 & 0.351 & 0.317 \\
\hline Number of births & $1.48(1-3)$ & $1.36(1-3)$ & $1.42(1-2)$ & 0.274 & 0.744 & 0.568 \\
\hline \multicolumn{7}{|l|}{ Years postpartum } \\
\hline$\leq 5, \mathrm{n}(\%)$ & $26(89.7)$ & $45(58.4)$ & $6(50.0)$ & $0.002^{\mathrm{a}}$ & $0.017^{\mathrm{a}}$ & 0.813 \\
\hline$>5, \mathrm{n}(\%)$ & $3(10.3)$ & 32 (41.6) & $6(50.0)$ & & & \\
\hline Lactation, $\mathrm{n}(\%)$ & $27(93.1)$ & $67(87.0)$ & $11(91.7)$ & 0.378 & 0.872 & 0.649 \\
\hline Abortion history, n (\%) & $9(31.0)$ & $36(46.8)$ & $6(50)$ & 0.144 & 0.251 & 0.834 \\
\hline $\begin{array}{l}\text { Frequency of abortion, } \\
\mathrm{n} \text { (range) }\end{array}$ & $1.25(1-2)$ & $1.72(1-4)$ & $2.33(1-6)$ & 0.156 & 0.414 & 0.931 \\
\hline \multicolumn{7}{|l|}{ Location } \\
\hline Around areola & $21(27.7)$ & $18(62.1)$ & & $0.002^{\mathrm{a}}$ & & \\
\hline Peripheral part & $56(72.3)$ & $11(37.9)$ & & & & \\
\hline
\end{tabular}

${ }^{a} \mathrm{P}<0.05$ was considered to indicate a statistically significant difference. GLM, granulomatous lobular mastitis; MDE, mammary duct ectasia.

Following comparative analysis, no statistically significant difference was observed in pregnancy, delivery, lactation and abortion between the GLM and MDE groups; however, a last delivery within 5 years was observed more frequently in patients of the GLM group $\left(\chi^{2}=9.878 ; \mathrm{P}=0.002\right)$. Compared with the overlapping group, the percentage of patients aged $<40$ years old was higher in the GLM group $\left(\chi^{2}=4.478\right.$; $\mathrm{P}=0.034)$. Furthermore, more patients in the GLM group had had their last delivery within the last 5 years $\left(\chi^{2}=6.36\right.$; $\mathrm{P}=0.012$ ).

Local manifestations were evaluated. The majority of patients were unilateral, excluding four bilateral cases diagnosed with MDE. Nipple retraction was observed in 17 patients of the GLM, 43 of the MDE and 10 of the overlapping groups. Nipple discharge was observed in two cases from the GLM and 13 from the MDE group. None of the 12 patients in the overlapping group complained of galactorrhea. A breast lump with or without pain was observed in the majority of patients from all three groups. Abscess formation occurred in 8 cases in the GLM, 38 in the MDE and 9 in the overlapping group. Some cases subsequently developed skin ulcers (Fig. 1). Ipsilateral axillary lymph node enlargement was sometimes observed. The detailed local manifestations are presented in Table II.

The statistical analysis revealed no difference in nipple retraction and galactorrhea between the GLM and MDE groups. The mass size of GLM was usually larger than that of MDE $(\mathrm{P}<0.001)$, while patients in the MDE group had a predisposition for breast abscess and skin ulcers $\left(\chi^{2}=4.062\right.$; $\mathrm{P}=0.044)$. Patients in the GLM group more frequently complained of breast pain $\left(\chi^{2}=7.256 ; P=0.007\right)$. Axillary lymph node enlargement occurred analogously in the three groups. Similar results in terms of developing breast abscess were obtained between the overlapping and MDE groups $\left(\chi^{2}=7.862 ; \mathrm{P}=0.005\right)$.

A total of 23 patients from the GLM group received sonographic examination. The majority of patients exhibited an irregular hypoechogenicity or inhomogeneous echos with obscured margins. A sonolucent fluid-filled area containing lots of spot-like echos was observed (Fig. 2A and B). A total of 72 cases from the MDE group received sonographic examination. The sonographic features of MDE were similar to those of GLM (Fig. 2C and D). Local high density or architectural distortion can be seen on the mammogram. Thickening and edema of the surface skin of the inflammation or nipple retraction can also be observed (Fig. 3). It is believed that local manifestation and sonography played an important role in the diagnosis of these patients and the differential diagnosis from breast carcinoma. However, the differentiation of GLM from MDE was a clinical dilemma. The detailed histopathological features are presented in Table III.

The most significant characteristic of GLM was perilobular granulomatous inflammation $\left(\chi^{2}=71.44 ; \mathrm{P}<0.001\right)$. 
Table II. Local manifestation of GLM, MDE and overlapped groups.

\begin{tabular}{|c|c|c|c|c|c|c|}
\hline \multirow[b]{2}{*}{ Characteristics } & \multirow[b]{2}{*}{ GLM (n=29) } & \multirow[b]{2}{*}{$\operatorname{MDE}(n=77)$} & \multirow[b]{2}{*}{ Overlapped $(n=12)$} & \multicolumn{3}{|c|}{ P-value } \\
\hline & & & & $\begin{array}{l}\text { GLM vs. } \\
\text { MDE }\end{array}$ & $\begin{array}{c}\text { GLM vs. } \\
\text { overlapped }\end{array}$ & $\begin{array}{l}\text { MDE vs. } \\
\text { overlapped }\end{array}$ \\
\hline Side, n (\%) & & & & 0.437 & 0.183 & 0.185 \\
\hline Right & $11(37.9)$ & $30(39.0)$ & $2(16.7)$ & & & \\
\hline Left & $18(62.1)$ & $43(55.8)$ & $10(83.3)$ & & & \\
\hline Bilateral & $0(0.0)$ & $4(5.2)$ & $0(0.0)$ & & & \\
\hline Nipple Retraction, n (\%) & $17(58.6)$ & $43(55.8)$ & $10(83.3)$ & 0.797 & 0.129 & 0.071 \\
\hline Galactorrhea, n (\%) & $2(6.9)$ & $13(16.9)$ & $0(0.0)$ & 0.188 & 0.351 & 0.123 \\
\hline Diameter of mass, $(\mathrm{cm})$ & & & & $<0.001^{\mathrm{a}}$ & $0.002^{\mathrm{a}}$ & $<0.001^{\mathrm{a}}$ \\
\hline Mean & 6.23 & 4.00 & 6.27 & & & \\
\hline Range & $3.0-10.0$ & $0.6-12.0$ & $2.0-14.0$ & & & \\
\hline Abscess/ulceration, n (\%) & $8(27.6)$ & $38(49.4)$ & $9(75.0)$ & $0.044^{\mathrm{a}}$ & $0.005^{\mathrm{a}}$ & 0.098 \\
\hline Pain & $27(93.1)$ & $52(67.5)$ & $12(100.0)$ & $0.007^{\mathrm{a}}$ & 0.351 & $0.020^{\mathrm{a}}$ \\
\hline Lymph node enlargement & $6(20.7)$ & $12(15.6)$ & $3(25.0)$ & 0.533 & 0.762 & 0.418 \\
\hline
\end{tabular}

${ }^{\text {aP }}<0.05$ was considered to indicate a statistically significant difference. GLM, granulomatous lobular mastitis; MDE, mammary duct ectasia.
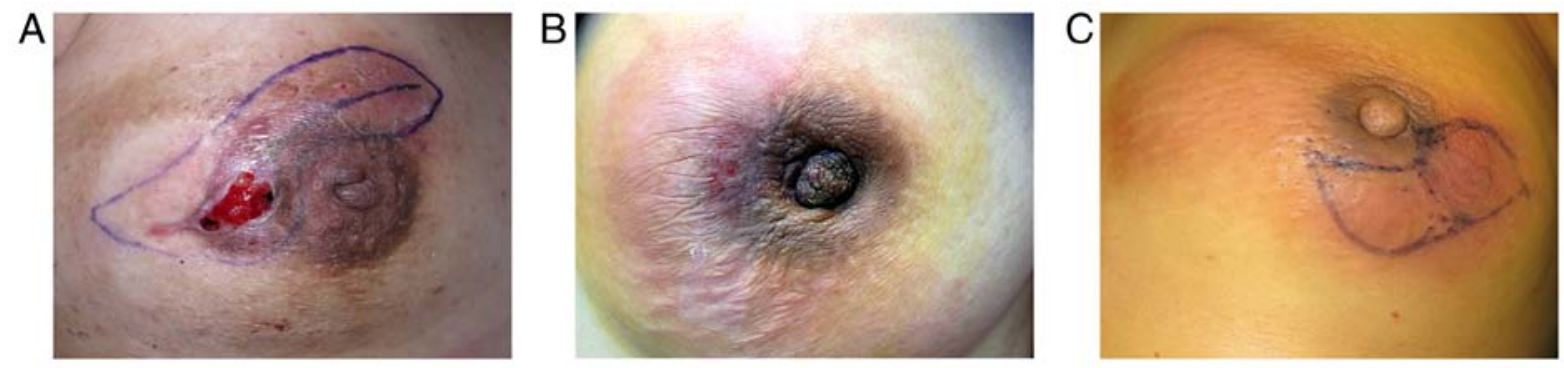

Figure 1. (A) Granulomatous lobular mastitis manifested as a painful tender breast lump, accompanied by nipple retraction, redness of skin, abscess and ulcers on the surface of the skin. (B) A patient with MDE suffering from hypophysoma presenting with a painful, tender breast lump, accompanied by nipple retraction, abscess formation and redness of surface skin. (C) An overlapping case manifested as a widely distributed breast lump, with nipple retraction, abscess formation, and redness of the skin surface. MDE, mammary duct ectasia.

Compared with the MDE group, intralobular microabscess and granulomas were more common in patients with GLM $(\mathrm{P}<0.001)$. Multinuclear giant cell infiltration in the local inflammatory focus was observed more frequently in GLM $\left(\chi^{2}=22.68 ; \mathrm{P}<0.001\right)$. Neutrophils were the most commonly observed intralobular inflammatory cells $\left(\chi^{2}=24.99 ; \mathrm{P}<0.001\right)$, with lymphocytes a close second. Plasmocytes were occasionally observed. MDE was identified as mammary duct dilation with inflammation of the duct wall and periductal tissue $(\mathrm{P}<0.001)$. Foam cells could be found in or around the duct wall $\left(\chi^{2}=38.44 ; \mathrm{P}<0.001\right)$. Intraductal secretion, periductal fibrosis and duct hyperplasia were more common in MDE than in GLM $(\mathrm{P}<0.001)$. Lymphocytes were the main type of inflammatory cells infiltrating the local inflammatory focus in MDE. A large number of plasmocytes was observed. Necrosis was identified in both the GLM and MDE groups, but the difference was not statistically significant. As expected, patients in the overlapping group exhibited the histopathological characteristics of both GLM and MDE simultaneously (Figs. 4 and 5).
The treatment strategy that followed for all three groups was wide resection of the tissue involved in inflammation and granulomas, with the administration of the necessary preoperative antibiotics (such as cefazolin sodium) for 3-7 days. Antibiotics sensitive to cocci bacteria were administered for 2-3 days following surgery. Prior to their final admission to hospital, 5 patients in the GLM, 21 in the MDE and 2 in the overlapping group had a history of abscess incision and drainage. Certain patients had previously experienced repeated recurrence, up to three times prior to treatment. Corticosteroids were not used in the treatment of all patients.

\section{Discussion}

GLM is considered as a rare chronic non-specific inflammatory lesion of the breast (19). It is histopathologically characterized by the presence of epithelioid and multinucleated giant cell granulomas confined to the central lobules with microabscesses in the absence of obvious etiology (20). MDE is commonly associated with pathological nipple discharge, 
Table III. Histopathological characteristics of GLM, MDE and overlapped groups.

\begin{tabular}{|c|c|c|c|c|c|c|}
\hline \multirow[b]{2}{*}{ Characteristics } & \multirow[b]{2}{*}{ GLM (n=29) } & \multirow[b]{2}{*}{$\operatorname{MDE}(n=77)$} & \multirow[b]{2}{*}{ Overlapped $(\mathrm{n}=12)$} & \multicolumn{3}{|c|}{ P-value } \\
\hline & & & & $\begin{array}{l}\text { GLM vs. } \\
\text { MDE }\end{array}$ & $\begin{array}{l}\text { GLM vs. } \\
\text { overlapped }\end{array}$ & $\begin{array}{l}\text { MDE vs. } \\
\text { overlapped }\end{array}$ \\
\hline Duct dilation & $6(20.7)$ & 75 (97.4) & $12(100.0)$ & $<0.001^{\mathrm{a}}$ & $<0.001^{\mathrm{a}}$ & 0.572 \\
\hline Periductal inflammation & $1(3.45)$ & $68(88.3)$ & $11(91.7)$ & $<0.001^{\mathrm{a}}$ & $<0.001^{\mathrm{a}}$ & 0.732 \\
\hline Periductal fibrosis & $1(3.45)$ & $72(93.5)$ & $12(100.0)$ & $<0.001^{\mathrm{a}}$ & $<0.001^{\mathrm{a}}$ & 0.364 \\
\hline Intraductal secretion & $1(3.45)$ & $69(89.6)$ & $10(83.3)$ & $<0.001^{\mathrm{a}}$ & $<0.001^{\mathrm{a}}$ & 0.522 \\
\hline Duct hyperplasia & $0(0.0)$ & $56(72.7)$ & $7(58.3)$ & $<0.001^{\mathrm{a}}$ & $<0.001^{\mathrm{a}}$ & 0.308 \\
\hline Periductal foam cell & $0(0.0)$ & $52(67.5)$ & $6(50.0)$ & $<0.001^{\mathrm{a}}$ & $<0.001^{\mathrm{a}}$ & 0.236 \\
\hline Plasmocyte & $5(17.2)$ & $26(33.8)$ & $5(41.7)$ & 0.095 & 0.098 & 0.593 \\
\hline Neutrophile granulocyte & $16(55.2)$ & $9(11.7)$ & $3(25.0)$ & $<0.001^{\mathrm{a}}$ & 0.078 & 0.209 \\
\hline $\begin{array}{l}\text { Perilobular granulomatous } \\
\text { inflammation }\end{array}$ & $29(100.0)$ & $9(11.7)$ & $11(91.6)$ & $<0.001^{\mathrm{a}}$ & 0.116 & $<0.001^{\mathrm{a}}$ \\
\hline \multicolumn{7}{|l|}{$\begin{array}{l}\text { Intralobular inflammatroy } \\
\text { cell }\end{array}$} \\
\hline $\mathrm{N}, \mathrm{P}, \mathrm{L}$ & $13(44.8)$ & $3(3.9)$ & $4(33.3)$ & $<0.001^{\mathrm{a}}$ & 0.479 & $<0.001^{\mathrm{a}}$ \\
\hline $\mathrm{N}, \mathrm{L} / \mathrm{N}$ & $14(48.3)$ & $5(6.5)$ & $6(50.0)$ & $<0.001^{\mathrm{a}}$ & 0.920 & $<0.001^{\mathrm{a}}$ \\
\hline $\mathrm{L}, \mathrm{P} / \mathrm{L}$ & $1(3.45)$ & $10(13.0)$ & $1(8.33)$ & 0.151 & 0.509 & 0.649 \\
\hline Intralobular Microabscess & $25(86.2)$ & $7(9.1)$ & $11(91.7)$ & $<0.001^{\mathrm{a}}$ & 0.627 & $<0.001^{\mathrm{a}}$ \\
\hline \multicolumn{7}{|l|}{$\begin{array}{l}\text { Features in Surrounding } \\
\text { tissue }\end{array}$} \\
\hline Granulomas & $26(89.7)$ & $27(35.1)$ & $10(83.3)$ & $<0.001^{\mathrm{a}}$ & 0.574 & $0.002^{\mathrm{a}}$ \\
\hline Microabscess & $24(82.8)$ & $23(29.9)$ & $8(66.7)$ & $<0.001^{\mathrm{a}}$ & 0.257 & $0.013^{\mathrm{a}}$ \\
\hline Multinuclear Giant Cell & $27(93.1)$ & $32(41.6)$ & $10(83.3)$ & $<0.001^{\mathrm{a}}$ & 0.337 & $0.007^{\mathrm{a}}$ \\
\hline Foam Cell & $16(55.2)$ & $43(55.8)$ & $4(33.3)$ & 0.951 & 0.203 & 0.146 \\
\hline Cholesterol crystal & $3(10.3)$ & $4(5.19)$ & $0(0.0)$ & 0.341 & 0.247 & 0.419 \\
\hline Calcification & $1(3.45)$ & $1(1.30)$ & $0(0.0)$ & 0.468 & 0.515 & 0.691 \\
\hline Necrosis & $1(3.45)$ & $5(6.49)$ & $0(0.0)$ & 0.545 & 0.515 & 0.364 \\
\hline
\end{tabular}

${ }^{\text {aP }}<0.05$ was considered to indicate a statistically significant difference. GLM, granulomatous lobular mastitis; MDE, mammary duct ectasia; $\mathrm{N}$, neutrophils; P, plasma cells; L, lymphocytes.

according to previously published literature (21). MDE is a type of periductal inflammatory disease of the breast. It is characterized by extralobular irregular ductal dilation with periductal fibrosis. Its clinical manifestations are usually similar to those of GLM, making the differential diagnosis, via both physical examination and imaging, challenging (22). Both of these chronic inflammatory diseases mimic breast carcinoma. The experience of the authors of the present study has demonstrated that they may also benefit from the same therapeutic strategy. The etiology and pathogenesis of GLM remains unclear. However, an association with pregnancy, lactation, locally autoimmune process, infection, hyperprolactinemia and chemical reaction induced by oral contraceptive pills has been reported in previously published articles (4,7-10).

After reviewing the literature, it was revealed that the majority of patients are of Mediterranean (Turkey and Jordan) and Asian (Arabia, China and Malaysia) origin (17). Although no obvious ethnic predisposition has been previously reported, a prevalence of GLM in specific ethnic populations has been mentioned in a number of reports $(18,23)$. According to the results of the present study, patients with GLM account for $3.5 \%$ of all cases of benign breast disease in Han Chinese women. The incidence rate in the Han Chinese population was higher than that in other populations, linking the occurrence of GLM to an ethnic predisposition (17).

Although factors such as pregnancy, lactation, locally autoimmune process, infection, hyperprolactinemia and chemical reaction induced by oral contraceptive pills have been considered as possible reasons for GLM, its etiology and pathogenesis remains unclear (4,7-10). A previous study supported the conclusion that patients with GLM are usually parous women with a recent history of pregnancy and delivery (15). According to the results of the present study, the percentage of parous women was similar between the GLM and MDE groups, but the interval between the onset of the disease and the patient's last delivery was statistically different $(\mathrm{P}=0.002)$. Patients with GLM have usually had a delivery within the last 5 years prior to developing the disease, suggesting that GLM may be associated with pregnancy and lactation. This was consistent 
A

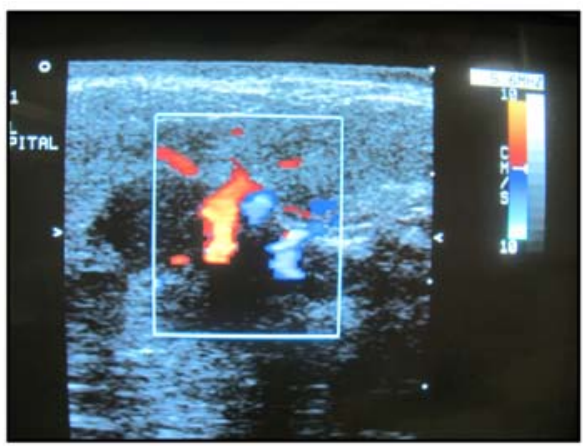

C

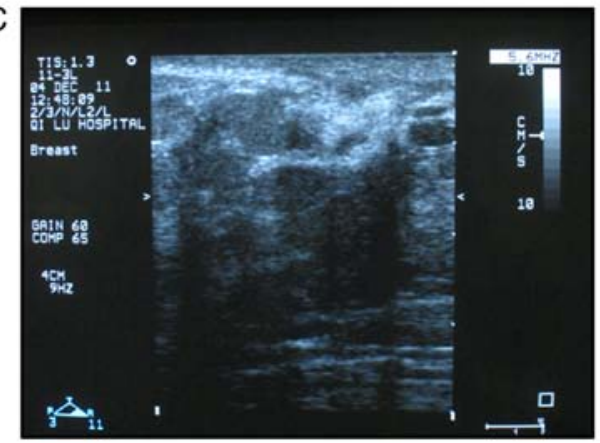

B

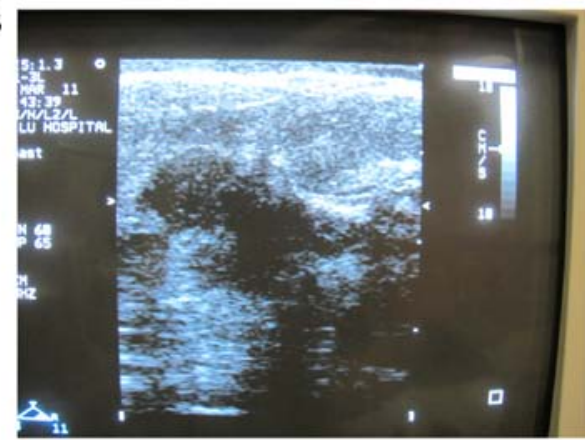

D

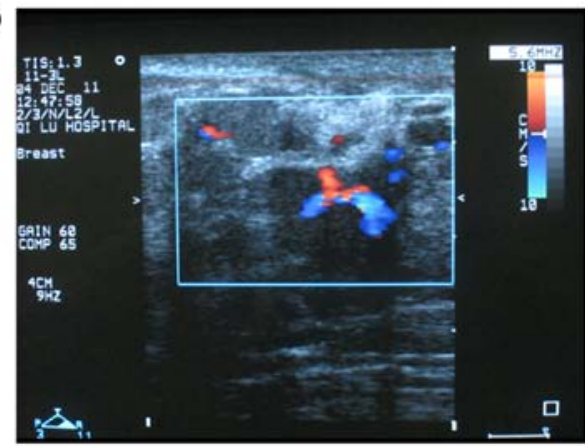

Figure 2. (A and B) A patient with GLM exhibited irregular undefined hypoechogenicity and sonolucent fluid-filled area containing detailed spot-like echos, and a strong blood flow signal. (C and D) An MDE patient showed undefined inhomogeneous hypoechogenicity, with mammary duct dilation and a strong blood flow signal. GLM, granulomatous lobular mastitis; MDE, mammary duct ectasia.

with the conclusion of Al-Khaffaf et al (18). Marriott et al (22) mentioned that extravasated lactational secretions may elicit a granulomatous inflammatory response by themselves. Cserni et al (8) reported that high levels of serum prolactin and subsequent excessive stimulation and lactational change may be potential causative factors for IGM.

Although it has been reported that the age of patients with GLM may range from 11 to 80 years (15), the high-risk group are women of childbearing age, between 30 and 40 years (6). In the results of the present study, no significant differences were observed in the mean age between those patients with GLM and those with $\mathrm{MDE}(\mathrm{P}=0.052)$, but the majority of patients with GLM were aged $<40$ years. Based on the authors' clinical experience, the local presentation of GLM is very similar to that of MDE, with breast lump being the primary complaint from the patient. However, accompanying breast pain occurs more frequently in GLM $(\mathrm{P}<0.01)$, and the mean diameter of a GLM mass is $6.23 \mathrm{~cm}$, which is larger than that of an MDE mass $(\mathrm{P}<0.001)$. This result is comparable with that obtained by Gurleyik et al (11). The present study also revealed that the prevalence of abscess or skin ulcers in patients with GLM was lower than that in patients with $\operatorname{MDE}(\mathrm{P}=0.044)$. To the best of our knowledge, this difference had not been well illustrated in previous articles.

The lack of specificity in the imaging techniques, such as ultrasound, mammography, MRI or CT, makes the diagnosis of GLM and MDE challenging. The exact diagnosis of GLM is even difficult when using fine needle aspiration cytology (24); however, it is feasible if the clinical presentation and imageology characteristics are also considered (25). Fortunately, significant histopathological differences between GLM and MDE were observed in the present

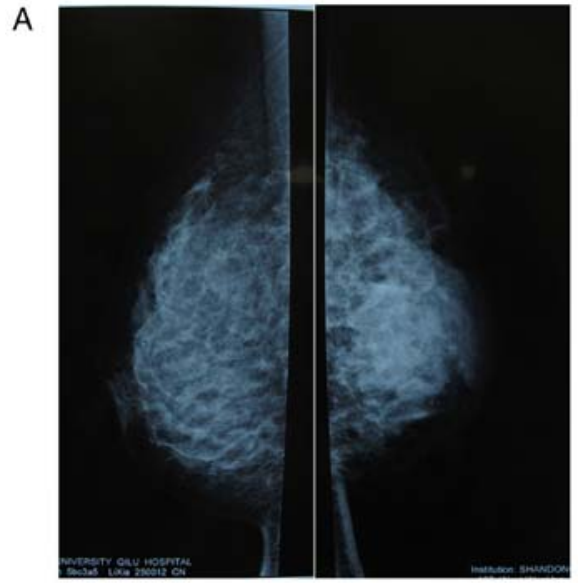

B

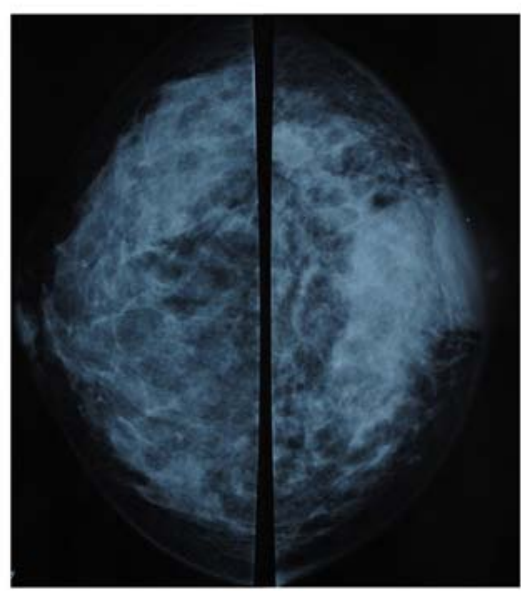

Figure 3. Mammographic appearance of mammary duct ectasia, showing asymmetric density accompanied by thickening and edema of the skin around the nipple. (A) Mediolateral oblique view. (B) Craniocaudal view. 
A
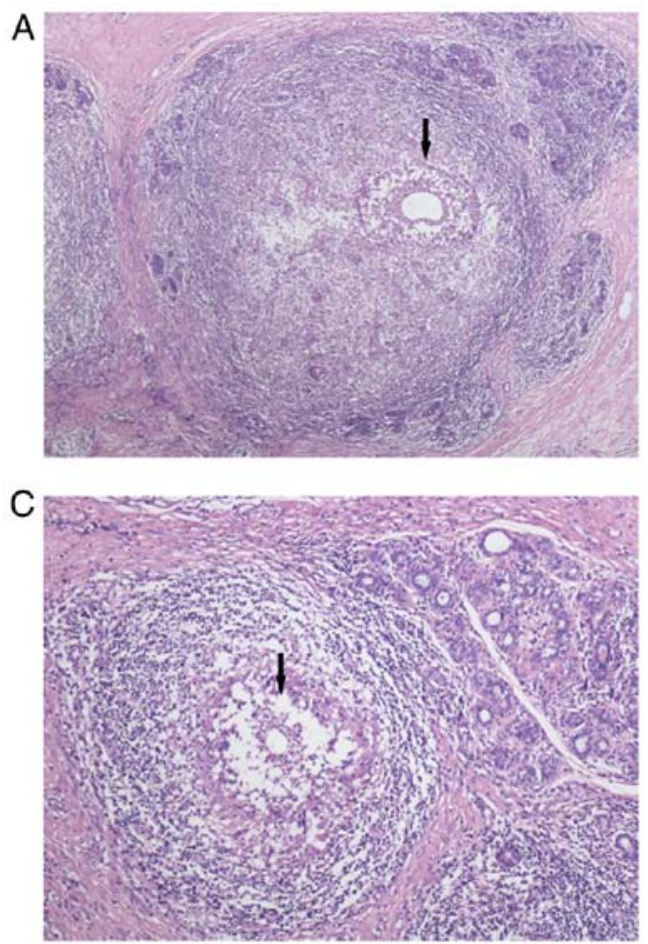

B

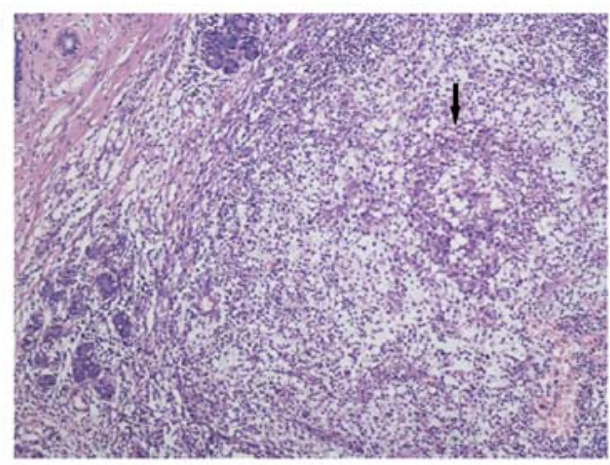

D

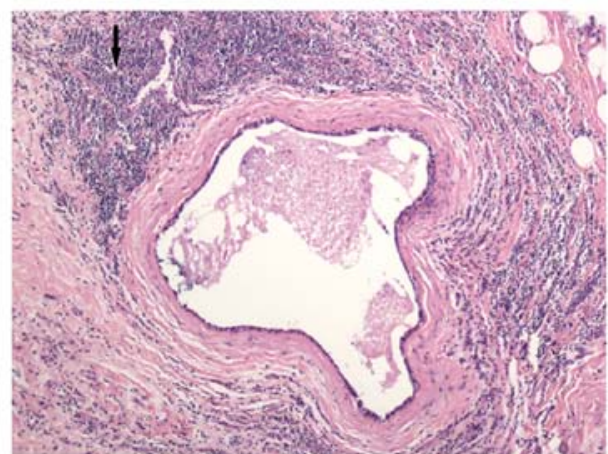

Figure 4. Typical histopathological features of (A-C) GLM and (D) MDE. (A) Intralobular granulomatous inflammation. (B) The normal structure of the lobule was damaged. (C) Centrilobular microabscess and lipid vacuoles. (D) Mammary duct dilation with concentrated intraductal secretions and chronic periductal inflammation. Lymphocyte and plasmocyte infiltration were observed with marked periductal fibrosis. GLM, granulomatous lobular mastitis; MDE, mammary duct ectasia. The magnification of hematoxylin and eosin staining was $\mathrm{x} 100$.

A

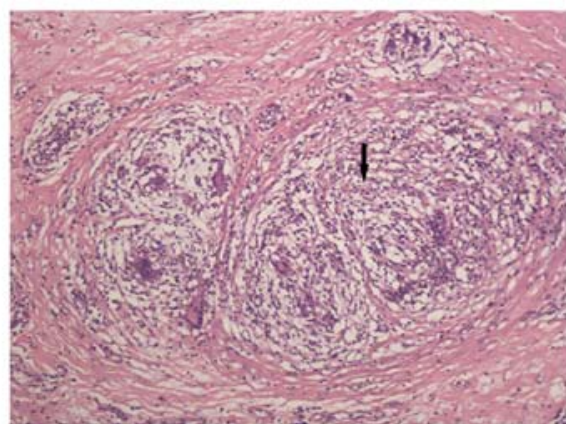

C

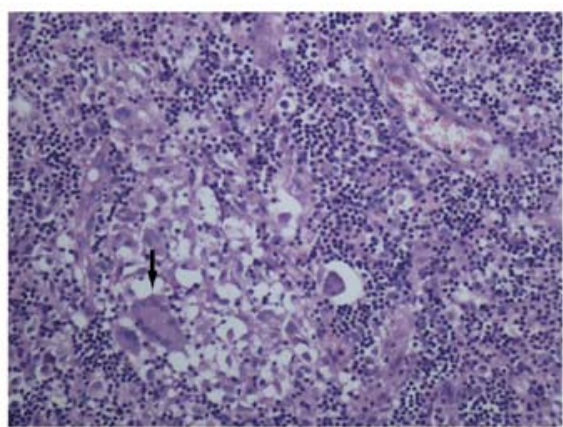

B

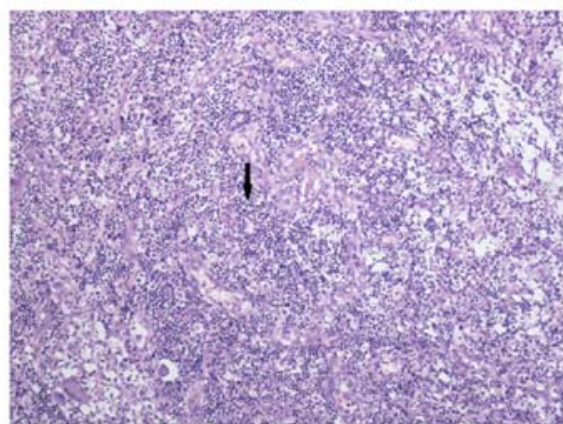

D

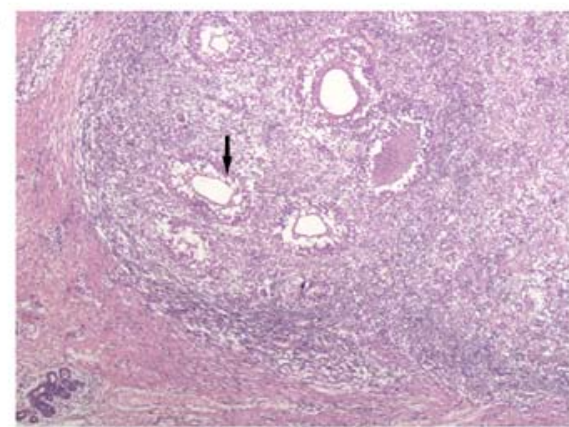

Figure 5. Characteristic appearance of GLM. (A) Intralobular granuloma formation. (B) A large number of inflammatory cells infiltrated the inflammatory focus, including neutrophil granulocytes, lymphocytes and a few plasmocytes. (C) Multinuclear giant cells surrounded by epithelioid macrophages, accompanied with inflammatory cell infiltration, were observed. (D) Several microabscesses formed inside the inflammatory focus. GLM, granulomatous lobular mastitis. The magnification of hematoxylin and eosin staining was x100.

study. The present study revealed that the most outstanding histological feature of GLM was perilobular granulomatous inflammation. Microabscess formation can be commonly observed in the center of the lobule or in the normal breast tissue surrounding the lesion. Multinuclear giant cells are commonly observed in the lesion, while inflammatory cells 
infiltrating the center of the lobule are usually neutrophil granulocytes. Lymphocytes are also common, but plasmocyte infiltration is rare. MDE is characterized by mammary duct dilatation, accompanied by inflammatory responses inside the duct wall or tissues surrounding the duct. The most common inflammatory cells infiltrating or surrounding the mammary duct is foam cells. Secretion inside the duct, fibrosis surrounding the duct, and ductal hyperplasia were significantly more common in MDE than in GLM $(\mathrm{P}<0.001)$. Duct dilatation may occur in GLM lesions, with the presence of inflammation inside or surrounding the duct, but the inflammatory response is not usually apparent. Both cholesterol crystals and calcification may occur in GLM. MDE may also be accompanied by cholesterol crystals and calcification, but this is not statistically different when compared with GLM.

Controversy remains when regarding the most effective therapeutic strategy of GLM. A number of conservative therapies have been demonstrated to be effective, including glucocorticoids, immunosuppressive drugs, antibiotics and so on (26-29). However, all conservative treatments are associated with a high risk of recurrence, and the majority of patients eventually require surgery. For the majority of surgeons, surgery is the most effective treatment for GLM and should be the preferred first-line approach. Thorough excision of the inflammatory tissue is the determinant of successful treatment (26-29). In the literature, recurrence can still not be completely avoided following surgery, with recurrence rates at 5.5-50.0\% (30-32). The experience of Akça et al (33) demonstrated that wide surgical excision was associated with a lower complication rate than that of limited excision. Negative surgical margins of inflammatory tissue are associated with a low recurrence rate (31); however, it is believed that it is difficult to accurately judge the margin during the operation. Therefore, excessive excision is inevitable in order to lower the risk of recurrence. In the present study, all patients received thorough excision of the inflammatory tissue, and even partial excision of the retracted nipple followed by nipple reconstruction. No recurrence was observed after the follow-up. However, the damage to the normal breast shape had a significant psychological effect on certain patients. Breast implants or breast reconstruction may be necessary in such cases.

In conclusion, GLM is a rare chronic non-specific inflammatory lesion of the breast. It is more prevalent in Han Chinese women than in other ethnicities. GLM and MDE have a very similar clinical presentation and may benefit from the same therapeutic strategy. There are, however, significant differences in the histopathological characteristics of GLM and MDE. The lack of specificity of imaging techniques makes it difficult to differentiate GLM from MDE or breast carcinoma in certain patients, unless histopathological diagnosis is used. Thorough excision of the inflammatory tissue, and even partial excision of the retracted nipple followed by breast implants or breast reconstruction, remains the most effective therapeutic strategy.

\section{Acknowledgements}

Not applicable.

\section{Funding}

The present study was supported by the National Natural Science Foundation of China (grant nos. 81672613 and 81602329), the Scientific Research Foundation of Shandong Province for Outstanding Young Scientist Award (grant no. BS2014YY055), the China Postdoctoral Science Foundation (grant no. 2015M572050), and the Key Research and Development Program of Shandong Province (grant nos. 2015GSF118035, 2016GGE2775 and 2015GSF118093).

\section{Availability of data and materials}

The datasets used and/or analyzed during the current study are available from the corresponding author on reasonable request.

\section{Authors' contributions}

LJ and XL designed the study. QY revised the experimental design. LJ, XL and BS acquired, analyzed and interpreted the data. XK and TM validated the experimental data. LJ, XL and QY verified the results of the experiment. All authors wrote the manuscript and revised it for important intellectual content.

\section{Ethics approval and consent to participate}

The present study was approved by the Ethics Committee on Scientific Research of Shandong University Qilu Hospital. Written and informed consent was obtained from all patients.

\section{Patient consent for publication}

Not applicable.

\section{Competing interests}

The authors declare that they have no competing interests.

\section{References}

1. Kessler E and Wolloch Y: Granulomatous mastitis: A lesion clinically simulating carcinoma. Am J Clin Pathol 58: 642-646, 1972.

2. Milward TM and Gough MH: Granulomatous lesions in the breast presenting as carcinoma. Surg Gynecol Obstet 130: 478-482, 1970

3. Miller F, Seidman I and Smith CA: Granulomatous mastitis. N Y State J Med 71: 2194-2195, 1971.

4. Davies JD and Burton PA: Postpartum lobular granulomatous mastitis. J Clin Pathol 36: 363, 1983.

5. Going JJ, Anderson TJ, Wilkinson S and Chetty U: Granulomatous lobular mastitis. J Clin Pathol 40: 535-540, 1987.

6. Pereira FA, Mudgil AV, Macias ES and Karsif K: Idiopathic granulomatous lobular mastitis. Int J Dermatol 51: 142-151, 2012.

7. Tournemaine N, Nomballais F, Weber J, Digabel-Chabay C, Bertrand AF and Cousin C: Granulomatous lesions of the breast. Their role in inflammatory breast pathology and their relations to lobular granulomatous mastitis. J Gynecol Obstet Biol Reprod (Paris) 16: 75-83, 1987 (In French).

8. Cserni G and Szajki K: Granulomatous lobular mastitis following drug-induced galactorrhea and blunt trauma. Breast J 5: 398-403, 1999.

9. Hmissa S, Sahraoui W, Missaoui N, Stita W, Mokni M, Yacoubi MT, Khairi H and Korbi S: Lobular idiopathic granulomatos mastitis. About 10 cases. Tunis Med 84: 353-357, 2006 (In French). 
10. Al Nazer MA: Idiopathic granulomatus lobular mastitis. A forgotten clinical diagnosis. Saudi Med J 24: 1377-1380, 2003.

11. Gurleyik G, Aktekin A, Aker F, Karagulle H and Saglamc A Medical and surgical treatment of idiopathic granulomatous lobular mastitis: A benign inflammatory disease mimicking invasive carcinoma. J Breast Cancer 15: 119-123, 2012.

12. Galea MH, Robertson JF, Ellis IO, Elston CW and Blamey RW: Granulomatous lobular mastitis. Aust N Z J Surg 59: 547-550, 1989.

13. Kfoury $\mathrm{H}$ and Al Bhlal L: Granulomatous lobular mastitis: A clinicopathological study of 112 cases. Ann Saudi Med 17: 43-46, 1997

14. Mote DG, Gungi RP, Satyanarayana V and Premsunder T: Granulomatous mastitis-a diagnostic dilemma. Indian J Surg 70: 241-243, 2008

15. Bani-Hani KE, Yaghan RJ, Matalka II and Shatnawi NJ: Idiopathic granulomatous mastitis: Time to avoid unnecessary mastectomies. Breast J 10: 318-322, 2004.

16. Wilson JP, Massoll N, Marshall J, Foss RM, Copeland EM and Grobmyer SR: Idiopathic granulomatous mastitis: In search of a therapeutic paradigm. Am Surg 73: 798-802, 2007.

17. Baslaim MM, Khayat HA and Al-Amoudi SA: Idiopathic granulomatous mastitis: A heterogeneous disease with variable clinical presentation. World J Surg 31: 1677-1681, 2007.

18. Al-Khaffaf B, Knox F and Bundred NJ: Idiopathic granulomatous mastitis: A 25-year experience. J Am Coll Surg 206: 269-273, 2008.

19. Sheybani F, Sarvghad M, Naderi HR and Gharib M: Treatment for and clinical characteristics of granulomatous mastitis. Obstet Gynecol 125: 801-807,2015.

20. Tuli R, O'Hara BJ, Hines J and Rosenberg AL: Idiopathic granulomatous mastitis masquerading as carcinoma of the breast: A case report and review of the literature. Int Semin Surg Oncol 4: 21, 2007.

21. Rahal RM, de Freitas-Júnior R and Paulinelli RR: Risk factors for duct ectasia. Breast J 11: 262-265, 2005.

22. Marriott DA, Russell J, Grebosky J, Wallace AM, Joste N and Royce ME: Idiopathic granulomatous lobular mastitis masquerading as a breast abscess and breast carcinoma. Am J Clin Oncol 30: 564-565, 2007.

23. Centers for Disease Control and Prevention (CDC): Idiopathic granulomatous mastitis in Hispanic women-Indiana, 2006-2008. MMWR Morb Mortal Wkly Rep 58: 1317-1321, 2009.
24. Tse GM, Poon CS, Law BK, Pang LM, Chu WC and Ma TK: Fine needle aspiration cytology of granulomatous mastitis. J Clin Pathol 56: 519-521, 2003.

25. Gupta RK: Fine needle aspiration cytology of granulomatous mastitis: A study of 18 cases. Acta Cytol 54: 138-141, 2010.

26. DeHertogh DA, Rossof AH, Harris AA and Economou SG: Prednisone management of granulomatous mastitis. N Engl J Med 303: 799-800, 1980.

27. Schmajuk G and Genovese MC: First report of idiopathic granulomatous mastitis treated with methotrexate monotherapy. J Rheumatol 36: 1559-1560, 2009.

28. Lai EC, Chan WC, Ma TK, Tang AP, Poon CS and Leong HT: The role of conservative treatment in idiopathic granulomatous mastitis. Breast J 11: 454-456, 2005.

29. Stary CM, Lee YS and Balfour J: Idiopathic granulomatous mastitis associated with corynebacterium sp. Infection. Hawaii Med J 70: 99-101, 2011.

30. Schelfout K, Tjalma WA, Cooremans ID, Coeman DC, Colpaert CG and Buytaert PM: Observations of an idiopathic granulomatous mastitis. Eur J Obstet Gynecol Reprod Biol 97: 260-262, 2001

31. Adler NR, Wolfe R, McArthur GA, Kelly JW, Haydon A, McLean CA and Mar VJ: Tumour mutation status and melanoma recurrence following a negative sentinel lymph node biopsy. Br J Cancer 118: 1289-1295, 2018

32. Ocal K, Dag A, Turkmenoglu O, Kara T, Seyit H and Konca K: Granulomatous mastitis: Clinical, pathological features, and management. Breast J 16: 176-182, 2010.

33. Akça T, Çolak T, Çağlıkülekçi M, Öcal K and Aydın S: Intestinal perforation in Wegener's granulomatosis: A case report. Ulus Travma Acil Cerrahi Derg 11: 348-351, 2005.

This work is licensed under a Creative Commons Attribution-NonCommercial-NoDerivatives 4.0 International (CC BY-NC-ND 4.0) License. 